\title{
Determinants of under-nutrition among women of reproductive age in Sindh, Pakistan: Findings from Pakistan Demographic and Health Survey, 2012-2013
}

\author{
Sumera A. Ali ${ }^{1}$, Savera A. Ali ${ }^{2}$, Shama Razzaq ${ }^{3}$, Shiyam S. Tikmani ${ }^{4}$, Ahreen Allana ${ }^{5}$, Narjis Rizvi ${ }^{4}$, Sarah Saleem ${ }^{4}$
}

\author{
AFFILIATION \\ 1 Department of Epidemiology, Mailman School of Public Health, \\ Columbia University, New York, United States \\ 2 Department of Nursing, University of Alberta, Edmonton, Canada \\ 3 Department of Community Medicine, Shalamar Medical and Dental \\ College, Lahore, Pakistan \\ 4. Department of Community Health Sciences, Aga Khan University, \\ Karachi, Pakistan \\ 5 Department of Pediatrics, Aga Khan University, Karachi, Pakistan
}

Popul. Med. 2020;2(August):26

\section{CORRESPONDENCE TO}

Shama Razzaq. Department of Community Medicine, Shalamar Medical and Dental College, Lahore, Punjab, 54000, Pakistan. E-mail: shama. razzak@gmail.com

\section{KEYWORDS}

Pakistan, undernutrition, women of reproductive age, parity

Received: 15 January 2020, Revised: 2 June 2020, Accepted: 13 July 2020

https://doi.org/10.18332/popmed/125364

\begin{abstract}
INTRODUCTION Undernutrition is a significant public health concern in the developing world and factors such as high parity and short birth intervals are significant contributors to maternal undernutrition. This study aimed to assess determinants of undernutrition among women of reproductive age in Sindh, Pakistan, using the national demographic health survey.

METHODS Data of 4050 ever married women of reproductive age from the Pakistan Demographic and Health Survey (PDHS) 2012-2013 were analyzed. These included sociodemographic and fertility-related variables. Logistic regression was applied to assess the determinants of undernutrition.

RESULTS Women having $\geq 5$ children were $47 \%$ less likely to
\end{abstract}

be undernourished compared to women having $<5$ children (OR=0.53; 95\% CI: 0.43-0.63). Undernourished women included those who belonged to rural areas (adjusted odds ratio, AOR=3.47; 95\% CI: 2.76-4.36), those who breastfed their infants (AOR=1.40; 95\% CI: 1.16-1.68), were smokers (AOR=4.35; 95\% CI: 2.58-7.34) or worked (AOR=1.22; 95\% CI: 1.09-1.47).

CONCLUSIONS The highest rates of undernourishment were found among working women as well as those who breastfed, smoked or belonged to the rural setting. We recommend that breastfeeding and working women should be provided awareness through teaching sessions and other means to improve their nutritional status as this subset of patients typically require additional calories.

\section{INTRODUCTION}

Maternal undernutrition is a significant concern in developing countries, especially of the South Asian region ${ }^{1}$. More than half of all women of reproductive age weigh less than $45 \mathrm{~kg}$ in this region ${ }^{2}$. Every year, more than 3.5 million women in developing countries die as a result of undernutrition ${ }^{3}$. Moreover, half of the world's undernourished women are found in three developing countries including Bangladesh, India and Pakistan ${ }^{1}$. Maternal undernutrition has been identified as a serious issue in Pakistan. According to the National Nutritional Survey of Pakistan 2011, 50\% of pregnant women in the country are anemic, $46 \%$ had vitamin A deficiency, while $47 \%$ and $68 \%$ were zinc and vitamin D deficient, respectively ${ }^{4}$.

Hence, undernutrition is a substantial underlying factor contributing to high maternal and childhood mortality in Pakistan and places an additional burden on the already limited resources of the country ${ }^{3}$. Since undernourished mothers are at higher risk of giving birth to underweight children, undernutrition can have a vicious, multigenerational impact ${ }^{5}$.

Studies have also demonstrated a close association between the mother's nutritional status and various pregnancy outcomes such as low birthweight, susceptibility to infections, and growth-challenged and developmentally delayed children ${ }^{6,7}$. Numerous factors can predict the nutritional status of a woman such as conditional influences, food production, cultural factors, socioeconomic and fertility-related factors ${ }^{8}$. For example, the fertility rate in Pakistan is very high and, on average, one Pakistani woman gives birth to 3.8 babies. Out of all women belonging to 
the reproductive age group in the country, only $35 \%$ have been documented to use contraception'. A high fertility rate and lack of birth spacing result in a continuous cycle of pregnancy and lactation, which can deplete the nutritional reserves of an already undernourished mother. Hence, the parity of a woman and birth spacing have a significant impact on the child's chances of survival ${ }^{3}$. A short inter-pregnancy interval does not give the mother sufficient time to recover from the birth process and replenish her stores of nutrients consumed during pregnancy, especially in the background of undernutrition ${ }^{10}$. Thus, too many (high parity) and too frequent pregnancies (shorter birth intervals) result in maternal undernutrition, which not only has an adverse effect on maternal health but also affects neonatal and infant health ${ }^{9}$. There is a dearth of research assessing the predictors of undernutrition status among women in Pakistan. The objective of this study was to assess the determinants of undernutrition among women of reproductive age in Sindh, Pakistan, using the national demographic health survey.

\section{METHODS}

The data of 4050 ever married women of reproductive age were extracted from a nationally representative sample, the Pakistan Demographic and Health Survey 2012-2013 completed by The National Institute of Population Studies (NIPS). The primary outcome variable was the nutritional status of the woman, which was dichotomized into a binary variable (undernourished and well nourished). The nutritional status of the women of reproductive age was determined using data on body mass index or BMI $\left(\mathrm{kg} / \mathrm{m}^{2}\right)$, which was categorized as $<18.5$ being 'undernourished' and $\geq 18.5$ 'adequately nourished.' In addition, sociodemographic and fertility-related variables such as age, place of residence, educational status, working status, wealth index, contraceptive usage, intention of pregnancy, parity, birth order, breastfeeding, smoking status, and other relevant variables were identified as independent variables from the PDHS data for further analysis. Hence, these data were part of PDHS during which literate data collectors were hired who translated and administered the questionnaires to the participants. These data collectors asked all questions in the local language of the participants. Data from the PDHS were publicly available data on a national level, so there was no need of IRB approval for analysis of the objective assessed in the study. In addition, they were secondary data, largely available for the public to analyze and answer specific research questions, without a need of IRB approval. We did not select the subjects ourselves rather these were selected by following multistage cluster sampling across the country.

\section{Statistical analysis}

Data analysis was carried out using STATA version 12 . Weighted analysis was done to obtain a representative sample in order to avoid over- or under-estimation by considering clusters, strata and sampling weights into the analysis for complex survey design. The normality of continuous data was assessed using histograms, p-p plots and by applying the Kolmogorov test. This was followed by computation of descriptive statistics for both continuous and categorical variables. Frequencies with percentages were calculated for the categorical variables including place of residence, women's level of education, working status of the women, and use of contraceptive methods.

To identify the factors associated with undernutrition, univariable analysis followed by multiple logistic regression was carried out. For each independent variable, crude odds ratios and adjusted odds ratios with their $95 \%$ confidence intervals and p-values were calculated.

Analysis was done by a purposeful selection method and all the variables that were selected in the univariable analysis were entered in the model. The significance of each independent variable in the multivariable analysis was assessed by $\mathrm{p}<0.05$.

\section{RESULTS}

\section{Sociodemographic characteristics of women by nutritional status}

Those aged 15-24 years comprised 8.6\% undernourished women and $6 \%$ adequately nourished women. Similarly, there were $47.4 \%$ undernourished women aged $25-34$ years compared with $30.3 \%$ adequately nourished, belonging to the same group (Table 1).

With respect to the ethnicity of the women, $45.9 \%$ of the undernourished women were found to be Sindhi speaking, $8 \%$ were Urdu speaking, $0.6 \%$ spoke Punjabi, and $45.6 \%$ spoke other regional languages. With regard to place of residence, $80.5 \%$ of the undernourished women were from rural areas. With respect to education, $79.7 \%$ of the undernourished women were not educated and $2.1 \%$ had received education for $\geq 12$ years (Table 1 ).

Amongst the undernourished group, 45.1\% women were working while $72.6 \%$ lived below the poverty line. Regarding the type of fuel used by the women, $19.3 \%$ of the undernourished women reported that they used gas for cooking as the primary type of fuel while $55.1 \%$ reported using either charcoal or wood. As for smoking, $4.8 \%$ of the undernourished women were found to be cigarette smokers, of these, $7.2 \%$ also reported tobacco chewing. With regard to knowledge about tuberculosis, $97 \%$ of the undernourished women had heard of the disease. Additionally, $39.4 \%$ of the undernourished women reported using a mosquito bed net for sleeping (Table 1).

\section{Fertility-related factors of participants by nutritional status of the woman}

With respect to parity, $44 \%$ of the undernourished women had $\leq 4$ children while $56 \%$ had $\geq 5$ children. Of the undernourished women, $38 \%$ reported using contraceptives while $97.1 \%$ reported at least one unwanted pregnancy. As for breastfeeding, $40.5 \%$ of the undernourished women reported that they breastfeed their child (Table 1). 
Table 1. Sociodemographic and fertility-related factors by nutritional status of women of reproductive age $(\mathrm{N}=4054)$

\begin{tabular}{l|c|c|}
\hline \multirow{2}{*}{ Characteristics } & Undernourished & Well nourished \\
\cline { 2 - 3 } Age (years) & $\mathbf{n}(\%)$ & n (\%) \\
\hline $15-24$ & $57(8.6)$ & $203(6)$ \\
$25-34$ & $315(47.4)$ & $1027(30.3)$ \\
$35-44$ & $192(28.9)$ & $1290(38.1)$ \\
$\geq 45$ & $101(15.2)$ & $868(25.6)$ \\
Education level & & \\
No education & $530(79.7)$ & $2238(66)$ \\
Primary & $91(13.7)$ & $417(12.3)$ \\
Middle to secondary & $30(4.5)$ & $426(12.6)$ \\
Intermediate and & $14(2.1)$ & $308(9.1)$ \\
above & &
\end{tabular}

\begin{tabular}{|c|c|c|}
\hline \multicolumn{3}{|l|}{ Literacy } \\
\hline Literate & $129(19.4)$ & $1106(32.6)$ \\
\hline Illiterate & $535(80.6)$ & $2282(67.4)$ \\
\hline \multicolumn{3}{|l|}{ Place of residence } \\
\hline Urban & $130(19.5)$ & $1671(49.3)$ \\
\hline Rural & $535(80.5)$ & $1718(50.7)$ \\
\hline \multicolumn{3}{|l|}{ Ethnicity } \\
\hline Urdu & $53(8.0)$ & $715(21.1)$ \\
\hline Punjabi & $4(0.6)$ & $145(4.3)$ \\
\hline Sindhi & 305 (45.9) & $1208(35.6)$ \\
\hline Other & $303(45.6)$ & $1321(39.0)$ \\
\hline \multicolumn{3}{|l|}{ Working status } \\
\hline Not working & 365 (54.9) & $2300(67.9)$ \\
\hline Working & $300(45.1)$ & $1089(32.1)$ \\
\hline \multicolumn{3}{|l|}{ Wealth index } \\
\hline Rich & $100(15)$ & $1462(43.2)$ \\
\hline Middle & $82(12.3)$ & $376(11.1)$ \\
\hline Poor & $483(72.6)$ & $1550(45.7)$ \\
\hline \multicolumn{3}{|l|}{ Type of cooking fuel } \\
\hline Gas & 128 (19.3) & $1706(50.4)$ \\
\hline Charcoal/wood & $366(55.1)$ & $1225(36.2)$ \\
\hline Straw/animal dung & 159 (23.9) & $428(12.6)$ \\
\hline Other & 11 (1.7) & $29(0.9)$ \\
\hline \multicolumn{3}{|l|}{ Smoking status } \\
\hline No & $633(95.2)$ & $3348(99.0)$ \\
\hline Yes & $32(4.8)$ & $35(1.0)$ \\
\hline \multicolumn{3}{|l|}{ Chew tobacco } \\
\hline No & 617 (92.8) & $3131(92.4)$ \\
\hline Yes & $48(7.2)$ & $258(7.6)$ \\
\hline \multicolumn{3}{|c|}{ Heard of tuberculosis } \\
\hline No & $20(3.0)$ & $40(1.2)$ \\
\hline Yes & $645(97.0)$ & 3349 (98.8) \\
\hline
\end{tabular}

Table 1. Continued

\begin{tabular}{|c|c|c|}
\hline \multirow[t]{2}{*}{ Characteristics } & Undernourished & Well nourished \\
\hline & n (\%) & n (\%) \\
\hline \multicolumn{3}{|l|}{$\begin{array}{l}\text { Mosquito bed net for } \\
\text { sleeping }\end{array}$} \\
\hline Yes & $262(39.4)$ & $768(22.7)$ \\
\hline No & $403(60.6)$ & $2620(77.3)$ \\
\hline \multicolumn{3}{|l|}{ Currently pregnant } \\
\hline Yes & $29(4.4)$ & $260(7.7)$ \\
\hline No & $636(95.6)$ & 3129 (92.3) \\
\hline \multicolumn{3}{|l|}{ Number of children } \\
\hline $0-4$ & $292(44.0)$ & $1157(34.1)$ \\
\hline$\geq 5$ & $372(56.0)$ & 2231 (65.9) \\
\hline \multicolumn{3}{|l|}{ Birth order } \\
\hline $2-3$ & $251(50.9)$ & $1228(47.0)$ \\
\hline $4-6$ & $186(37.7)$ & $976(37.3)$ \\
\hline$\geq 7$ & $56(11.4)$ & $410(15.7)$ \\
\hline \multicolumn{3}{|l|}{ Contraceptive usage } \\
\hline Yes & $253(38.0)$ & $1212(35.8)$ \\
\hline No & $412(62.0)$ & $2177(64.2)$ \\
\hline \multicolumn{3}{|l|}{ Pregnancy intention } \\
\hline Wanted & $19(2.9)$ & $245(7.2)$ \\
\hline Unwanted & $645(97.1)$ & $3144(92.8)$ \\
\hline \multicolumn{3}{|l|}{ Fertility preference } \\
\hline Wants another child & $219(32.9)$ & $829(24.5)$ \\
\hline $\begin{array}{l}\text { Does not want another } \\
\text { child }\end{array}$ & $446(67.1)$ & $2560(75.5)$ \\
\hline \multicolumn{3}{|l|}{ Breastfeeding } \\
\hline No & $396(59.5)$ & $2485(73.3)$ \\
\hline Yes & $269(40.5)$ & $904(26.7)$ \\
\hline \multicolumn{3}{|l|}{$\begin{array}{l}\text { Duration of } \\
\text { breastfeeding }\end{array}$} \\
\hline Never breastfed & $10(4.6)$ & $26(3.4)$ \\
\hline $\begin{array}{l}\text { Ever breastfed, } \\
\text { not currently } \\
\text { breastfeeding }\end{array}$ & $125(57.9)$ & $504(65.4)$ \\
\hline Still breastfeeding & $81(37.5)$ & $241(31.3)$ \\
\hline
\end{tabular}

\section{Determinants of undernutrition: Findings of univariable analysis}

Sociodemographic factors

We found that younger women were 2.41 times more likely to be undernourished compared to older women $(\mathrm{OR}=2.41$; 95\% CI: 1.68-3.45). Women with no formal education were 5.25 times more likely to be undernourished compared to women who had received formal education (OR=5.25; $95 \%$ CI: 3.04-9.07). Similarly, working women were 1.73 times more likely to be undernourished compared to non-working women (OR=1.73; 95\% CI: 1.47-2.05). Those residing in rural 
areas had 4.01 times greater odds of being undernourished compared to women from urban areas (OR=4.01; 95\% CI: 3.27-4.92). Women living below the poverty line were 4.56 times more likely to be undernourished compared with those who were financially well to do (OR=4.56; 95\% CI: 3.68-5.72). Those who smoked had a 4.90 times greater likelihood of being undernourished compared to non-smokers (OR=4.90; 95\% CI: 3.01-7.97) (Table 2).

Table 2. Association between sociodemographic characteristics with undernutrition among married women of reproductive age $(\mathrm{N}=4054)$

\begin{tabular}{|c|c|c|c|}
\hline Characteristics & OR & $95 \%$ CI & $\mathbf{p}^{*}$ \\
\hline Age (years) & & & $<0.001$ \\
\hline $15-24$ & 2.41 & $1.68-3.45$ & \\
\hline $25-34$ & 2.62 & $2.06-3.34$ & \\
\hline $35-44$ & 1.27 & $0.98-1.64$ & \\
\hline$\geq 45$ & 1 & & \\
\hline
\end{tabular}

\section{Education level}

$<0.001$

Intermediate and above

Middle to secondary

1

Primary education

$1.59 \quad 0.82-3.05$

No education

$4.83 \quad 2.69-8.67$

$5.25 \quad 3.04-9.07$

$\begin{array}{llll}\text { Literacy } & & & <0.001 \\ \text { Literate } & 1 & & \\ \text { Illiterate } & 2.04 & 1.63-2.46\end{array}$

Working status $\quad<0.001$

No 1

Yes

$1.73 \quad 1.47-2.05$

\section{Place of residence}

1

Urban

1

Rura

$4.01 \quad 3.27-4.92$

\section{Ethnicity}

Urdu

1

Punjabi

$0.38 \quad 0.14-1.07$

Sindhi

$3.42 \quad 2.52-4.65$

Other

$3.11 \quad 2.29-4.23$

\section{Wealth index}

1

Middle

$\begin{array}{ll}3.17 & 2.32-4.34 \\ 4.56 & 3.68-5.72\end{array}$

Poor

\section{Type of cooking fuel}

Gas

Charcoal/wood

1

Straw/animal dung

$3.97 \quad 3.20-4.91$

Other

$4.93 \quad 3.82-6.36$

$5.02 \quad 2.46-10.24$

Smoking cigarettes

No

Yes

\section{1}

$4.90 \quad 3.01-7.97$
Table 2. Continued

\begin{tabular}{|c|c|c|c|}
\hline Characteristics & OR & $95 \%$ CI & $\mathbf{p}^{*}$ \\
\hline Chew tobacco & & & $>0.05$ \\
\hline No & 1 & & \\
\hline Yes & 0.95 & $0.69-1.30$ & \\
\hline Heard of tuberculosis & & & $<0.001$ \\
\hline No & 1 & & \\
\hline Yes & 0.39 & $0.23-0.68$ & \\
\hline Mosquito bed net for sleeping & & & $<0.001$ \\
\hline Yes & 1 & & \\
\hline No & 0.45 & $0.38-0.53$ & \\
\hline
\end{tabular}

*All variables with $\mathrm{p}<0.05$ were considered as significant for multivariable analysis.

\section{Fertility-related factors}

Women with $\geq 5$ children were $33 \%$ less likely to be undernourished compared to women having $<5$ children (OR=0.67; 95\% CI: 0.56-0.78). Those with intended pregnancies were 2.58 times more likely to be undernourished compared with those with an unintended pregnancy. Women breastfeeding their children were 1.87 times more likely to be undernourished compared to women who did not breastfeed (OR=1.87; 95\% CI: 1.57-2.22) (Table 3).

\section{Determinants of undernutrition: Findings of multivariable analysis}

The multivariable analysis found that women having

Table 3. Association of fertility-related factors with undernutrition among married women of reproductive age $(\mathrm{N}=4054)$

\begin{tabular}{|c|c|c|c|}
\hline Characteristics & OR & $95 \% \mathrm{CI}$ & $\mathbf{p}^{*}$ \\
\hline Currently pregnant & & & $<0.001$ \\
\hline Yes & 1 & & \\
\hline No & 1.80 & $1.22-2.67$ & \\
\hline Parity & & & $<0.001$ \\
\hline $0-4$ & 1 & & \\
\hline$\geq 5$ & 0.67 & $0.56-0.78$ & \\
\hline Contraceptive use & & & $<0.001$ \\
\hline Yes & 1 & & \\
\hline No & 0.90 & $0.76-1.07$ & \\
\hline Pregnancy intention & & & $<0.001$ \\
\hline No & 1 & & \\
\hline Yes & 2.58 & $1.61-4.13$ & \\
\hline Fertility preference & & & $<0.001$ \\
\hline Wants another child & 1 & & \\
\hline Does not want another child & 0.66 & $0.55-0.79$ & \\
\hline Breastfeeding & & & $<0.001$ \\
\hline Yes & 1 & & \\
\hline No & 1.87 & $1.57-2.22$ & \\
\hline
\end{tabular}

*All variables with $\mathrm{p}<0.05$ were considered as significant for multivariable analysis. OR: Odds ratio. 95\% CI: 95\% Confidence Intervals 
$\geq 5$ children were $47 \%$ less likely to be undernourished compared to women having $<5$ children $(\mathrm{AOR}=0.53 ; 95 \%$ CI: $0.43-0.63)$. Those from rural areas were 3.47 times likely to be undernourished compared to women from urban areas (AOR=3.47; 95\% CI: 2.76-4.36). Similarly, working status increased the likelihood of undernutrition by 1.22 times (AOR=1.22; 95\% CI: 1.09-1.47). Women who smoked cigarettes were 4.35 times likely to be undernourished compared to those who did not smoke (AOR $=4.35$; 95\% CI: 2.58-7.34). Non-pregnant women were 2.22 times more likely to be undernourished compared to pregnant women (AOR=2.22; 95\% CI: 1.46-3.30). Women who breastfed were 1.40 times more likely to be undernourished compared to women not breastfeeding their children (AOR=1.40; 95\% CI: 1.16-1.68) (Table 4).

Table 4. Determinants of undernutrition among women of reproductive age $(\mathrm{N}=4054)$

\begin{tabular}{|c|c|c|c|}
\hline Characteristics & AOR & $95 \% \mathrm{CI}$ & $\mathbf{p}^{*}$ \\
\hline Parity & & & $<0.001$ \\
\hline $0-4$ & 1 & & \\
\hline$\geq 5$ & 0.53 & $0.43-0.63$ & \\
\hline Place of residence & & & $<0.001$ \\
\hline Urban & 1 & & \\
\hline Rural & 3.47 & $2.76-4.36$ & \\
\hline Working status & & & $<0.001$ \\
\hline No & 1 & & \\
\hline Yes & 1.22 & $1.09-1.47$ & \\
\hline Cigarette smoking & & & $<0.001$ \\
\hline No & 1 & & \\
\hline Yes & 4.35 & $2.58-7.34$ & \\
\hline Heard of tuberculosis & & & $<0.001$ \\
\hline Yes & 1 & & \\
\hline No & 2.14 & $1.18-3.90$ & \\
\hline Mosquito bed net for sleeping & & & $<0.001$ \\
\hline Yes & 1 & & \\
\hline No & 0.638 & $0.52-0.77$ & \\
\hline \multicolumn{4}{|l|}{ Pregnant } \\
\hline Yes & 1 & & \\
\hline No & 2.22 & $1.46-3.30$ & \\
\hline \multicolumn{4}{|l|}{ Breastfeeding } \\
\hline No & 1 & & \\
\hline Yes & 1.40 & $1.16-1.68$ & \\
\hline
\end{tabular}

*All variables with $\mathrm{p}<0.05$ were considered as significant for multivariable analysis. AOR: adjusted odds ratio

\section{DISCUSSION}

This data analysis from cross-sectional, nationally representative surveys conducted throughout the province of Sindh, Pakistan, provides evidence for relationships between parity and other socioeconomic and fertility-related factors with the nutritional status of women.
It demonstrates that parity is protective against undernutrition, as women with $\geq 5$ children were less likely to be undernourished compared with women with $<5$ children. Our findings are consistent with studies conducted in Mexico, North Africa/West Asia and China, where a weak to moderate positive association was found between parity and increased BMI ${ }^{11,12}$. These findings can be explained by the fact that cumulative cycles of post-partum weight retention are the primary mechanism by which parity leads to increased $\mathrm{BMI}^{13,14}$. Literature shows that the excess gestational weight gain can lead to post-partum weight retention and has been associated with increased weight gain in the long-term ${ }^{15,16}$. Lifestyle factors, including physical activity and dietary intake in the post-partum period can also be associated with post-partum weight retention, which in turn, determines the nutritional status of the mother. In addition to this, women with low parity might also be younger compared to those with high parity, which is consistent with our finding of younger women being more undernourished compared with older women.

These findings of a relationship between parity-related weight and nutritional status suggest a need for the development and implementation of programs to prevent and treat parity-related obesity in developing countries. Such programs could include efforts to prevent post-partum weight retention by promoting exclusive breastfeeding concomitant with moderate levels of physical activity. Moreover, younger women with low parity should be targeted for counseling regarding balanced and adequate diet to improve their nutritional status.

With respect to the place of residence, it was found that women living in rural areas were more likely to be undernourished compared to women belonging to urban areas. This finding is consistent with other studies conducted across the world ${ }^{17-19}$. Widespread poverty and lower socioeconomic conditions in rural areas might be possible factors that explain the high prevalence of undernutrition among women of reproductive age. For instance, undernutrition has been significantly associated with various factors like unskilled labor, financial constraints, overcrowding, households without electricity and tap water. These are also some of the major problems faced by women residing in rural areas ${ }^{19}$.

It is recommended that programs be designed to improve the nutritional status of women living in remote areas of Pakistan. During the past few years, many nutritional programs have been initiated by governmental and nongovernmental organizations ${ }^{20}$. Some of these programs focus on raising awareness among the population, while others focus on either directly supplying nutrients or fortification of dietary components. However, the root causes of the problem like illiteracy, poverty, and socioeconomic deprivations, are still being neglected ${ }^{21}$.

With regard to occupation, working women were more likely to be undernourished compared to non-working 
women of reproductive age. These findings might be due to the fact that working mothers have a greater energy expenditure that contributes to a lower bodyweight and BMI. However, literature supporting this evidence is very scarce, but these findings are consistent with the study conducted in Bangladesh, where females who worked 15-23 days per month had significantly better BMIs than those who worked $>23$ days per month ${ }^{19}$. These findings were inconsistent with the study conducted in Marzi Pura Faisalabad, Pakistan, where it was found that working status had a positive association with adequate nutrition and $\mathrm{BMI}^{22}$. These differences in findings may be because of the differences in study setting, sample size, and study population.

With respect to smoking status, women who smoked were more likely to be undernourished compared to nonsmokers. This finding can be explained by the biological fact that smoking reduces appetite and provides satiety. These findings are consistent with a study conducted in Styria, in southeast Austria ${ }^{23}$. Thus, one might expect that women who smoke would be more undernourished because of their poor appetite and diet. Moreover, smokers are more likely to indulge in other activities like tobacco chewing, bidi or huka use, which in turn deteriorate their nutritional status compared to their non-smoking counterparts. These women should be targeted for continuous counseling, and strategies need to be designed to alter the behavior of these women, not only to improve their nutritional status but also the nutritional status of their children.

With respect to breastfeeding, it was found that women who were breastfeeding their children were also more likely to be undernourished compared to the women not breastfeeding their children. These findings are in line with studies across the world that have found that breastfeeding contributes to maternal undernourishment ${ }^{24}$. This is a significant finding for women belonging to rural areas that do not have access to a balanced diet and have high fertility rates. Therefore, their body reserves are not adequately replenished, which creates a vicious circle of undernutrition ${ }^{8}$.

The public health implications of these findings depend on the context; greater maternal weight losses may be beneficial in healthy populations where women are already sufficiently nourished and they have access to a balanced diet, but detrimental in undernourished populations where women are mostly undernourished due to multiple causes like illiteracy, poverty, and lack of access to a nutritious diet. It is recommended that women who breastfeed their children take in extra calories to replenish their body reserves to prevent undernutrition ${ }^{8}$. Hence, these mothers should be adequately counseled about the intake of a balanced diet while breastfeeding their children.

It was also found that non-pregnant mothers were more likely to be undernourished compared to the pregnant mothers. These findings might be because of the physiological weight gain during pregnancy. Moreover, traditionally, Pakistani women who are pregnant are culturally encouraged to consume more calories compared to those who are non-pregnant. This may also explain the above finding of a good nutritional status during pregnancy. Although pregnancy increases the weight of the mother and pregnant women also tend to consume more calories during pregnancy, a balanced diet is also equally important for women who are married but not pregnant. Married and nonpregnant women are in their preconception phase, which is considered the right time to start adequate nutrition ${ }^{25,26}$. Studies have also found that maternal undernutrition during the first trimester of pregnancy carries the greatest risk for fetal development and so correcting nutritional status in early pregnancy is likely to yield the greatest benefits for both the mother and the offspring ${ }^{25,26}$. Thus, adequate nutrition should be provided to women during the preconception period to avoid short-term and long-term adverse maternal and neonatal outcomes.

\section{Strengths and limitations}

This data analysis was conducted on a large and nationally representative sample of women in Pakistan using the PDHS 2012-2013. Hence, the findings can be generalized to the Pakistani population as well as to other regional countries that share similar sociodemographic characteristics.

Moreover, the survey covered various sociodemographic and health-related variables, which were analyzed to measure the association between parity and women's nutritional status while adjusting for confounders. Additionally, weighted analysis was done to obtain representative estimates and to avoid under- or overestimation while analyzing the data.

One limitation of the study is its cross-sectional nature. Therefore, any association between the various predictors, especially parity and nutritional status, needs to be interpreted cautiously. Secondly, a key limitation of our study was the use of BMI as the only measure of nutritional status, which might not predict the true nutritional status of the women. Thus, stronger observational and analytical studies need to be carried out in the future to assess the association between parity and other predictors of nutritional status in women.

\section{CONCLUSIONS}

Women who breastfed, worked, smoked, or belonged to rural areas were found to be the most undernourished. Our analysis suggests that undernutrition is likely to occur when women do not have access to a balanced diet and this can be determined from their place of residence, breastfeeding and pregnancy status, as well as whether or not they work. We recommend that rural women who breastfeed their children, as well as work, be targeted for awareness on balanced nutrition. The proximal as well as distal or root causes of undernutrition need to be explored and addressed in the future to improve the nutrition of women of reproductive age. 


\section{REFERENCES}

1. Gillespie S. Malnutrition in South Asia: A regional profile. Kathmandu, Nepal: UNICEF Regional Office for South Asia; 1997.

2. Mason J, Hunt J, Parker D, Jonsson U. Investing in Child Nutrition in Asia. Asian Development Review. 1999;17(1,2):1-32. https:// www.adb.org/sites/default/files/publication/27918/investingchild-nutrition-asia.pdf. Accessed June 2, 2020.

3. Black RE, Allen LH, Bhutta ZA, et al. Maternal and child undernutrition: global and regional exposures and health consequences. Lancet. 2008;371(9608):243-260. doi:10.1016/s0140-6736(07)61690-0

4. Pakistan National Nutrional Survey 2011. Pakistan: Aga Khan University, Pakistan Medical Research Council (PMRC), Ministry of Health, Pakistan; 2012. https://www.mhinnovation.net/sites/default/ files/downloads/innovation/research/Pakistan\%20National\%20 Nutrition\%20Survey\%202011.pdf. Accessed June 2, 2020.

5. Landis S, Lokomba V, Ananth C, et al. Impact of maternal malaria and under-nutrition on intrauterine growth restriction: a prospective ultrasound study in Democratic Republic of Congo. Epidemiol Infect. 2009;137(2):294-304. doi:10.1017/s0950268808000915

6. Khan MN, Rahman MM, Shariff AA, Rahman MM, Rahman MS, Rahman MA. Maternal undernutrition and excessive body weight and risk of birth and health outcomes. Arch Public Health. 2017;75(1):12. doi:10.1186/s13690-017-0181-0

7. Triunfo $S$, Lanzone A. Impact of maternal under nutrition on obstetric outcomes. J Endocrinol Invest. 2015;38(1):31-38. doi:10.1007/s40618-014-0168-4

8. Park K. Park's Text Book of Preventive and Social Medicines. Jabalpur, India: Banarsidas Bhanot Publishers; 2017.

9. National Institute of Population Studies (NIPS), ICF International. Pakistan Demographic and Health Survey 2012-13. Islamabad, Pakistan and Calverton, MA: NIPS and ICF International; 2013. https://dhsprogram.com/pubs/pdf/ fr290/fr290.pdf. Accessed June 2, 2020.

10. Mahmood A. Determinants of neonatal and postneonatal mortality in Pakistan. Pakistan Development Review. 2002;41(4):723-744. doi:10.30541/v41i4iipp.723-744

11. Arroyo P, Avila-Rosas H, Fernandez V, Casanueva E, Galvan D. Parity and the prevalence of overweight. Int J Gynaecol Obstet. 1995;48(3):269-272. doi:10.1016/0020-7292(94)02284-6

12. Wen W, Gao YT, Shu XO, et al. Sociodemographic, behavioral, and reproductive factors associated with weight gain in Chinese women. Int J Obes. 2003;27(8):933-940. doi:10.1038/sj.ijo.0802318

13. Rooney BL, Schauberger CW, Mathiason MA. Impact of perinatal weight change on long-term obesity and obesityrelated illnesses. Obstet Gynecol. 2005;106(6):1349-1356.

CONFLICTS OF INTEREST

The authors have completed and submitted the ICMJE Form for Disclosure of Potential Conflicts of Interest and none was reported.

FUNDING

There was no source of funding for this research.

AUTHORS' CONTRIBUTIONS

The manuscript was prepared and conceptualized by SAA who also did

\section{doi:10.1097/01.aog.0000185480.09068.4a}

14. Olson CM, Strawderman MS, Hinton PS, Pearson TA. Gestational weight gain and postpartum behaviors associated with weight change from early pregnancy to $1 \mathrm{y}$ postpartum. Int J Obes. 2003;27(1):117-127. doi:10.1038/sj.ijo.0802156

15. Butte NF, Ellis KJ, Wong WW, Hopkinson JM, Smith EB. Composition of gestational weight gain impacts maternal fat retention and infant birth weight. Am J Obstet Gynecol. 2003;189(5):1423-1432. doi:10.1067/s0002-9378(03)00596-9

16. Rossner S. Weight gain in pregnancy. Hum Reprod. 1997;12(suppl 1):110-115. doi:10.1093/humrep/12.suppl_1.110

17. Pryer JA, Rogers S. Epidemiology of undernutrition in adults in Dhaka slum households, Bangladesh. Eur J Clin Nutr. 2006;60(7):815-822. doi:10.1038/sj.ejcn.1602385

18. Baqui AH, Arifeen SE, Amin S, Black RE. Levels and correlates of maternal nutritional status in urban Bangladesh. Eur J Clin Nutr. 1994;48(5):349-357. PMID:8055851.

19. Pryer JA, Rogers S, Rahman A. Factors affecting nutritional status in female adults in Dhaka slums, Bangladesh. Soc Biol. 2003;50(3-4):259-269. doi:10.1080/19485565.2003.9989075

20. Badruddin SH, Agha A, Peermohamed H, Rafique G, Khan KS, Pappas G. Tawana project-school nutrition program in Pakistan--its success, bottlenecks and lessons learned. Asia Pac J Clin Nutr. 2008;17(S1):357-360. PMID:18296378.

21. Niazi AK, Niazi SK, Baber A. Nutritional programmes in Pakistan: a review. J Med Nutr Nutraceut. 2012;1(2):98. doi:10.4103/2278-019x.101297

22. Sattar A, Shahbaz B, Rehman UN, Badar B. Factors affecting BMI; Assessment of the effect of sociodemographic factors on BMI In the population of Ghulam Mohammad Abad Faisalabad. Professional Med J. 2013;20(6):956-964.

23. Rasky E, Stronegger WJ, Freidl W. The relationship between body weight and patterns of smoking in women and men. Int J Epidemiol. 1996;25(6):1208-1212. doi:10.1093/ije/25.6.1208

24. Dewey KG, Cohen RJ, Brown KH, Rivera LL. Effects of exclusive breastfeeding for four versus six months on maternal nutritional status and infant motor development: results of two randomized trials in Honduras. J Nutr. 2001;131(2):262-267. doi:10.1093/jn/131.2.262

25. Wu G, Imhoff-Kunsch B, Girard AW. Biological mechanisms for nutritional regulation of maternal health and fetal development. Paediatr Perinat Epidemiol. 2012;26(s1):4-26. doi:10.1111/j.1365-3016.2012.01291.x

26. Rasmussen KM, Habicht JP. Maternal supplementation differentially affects the mother and newborn. J Nutr. 2010;140(2):402-406. doi:10.3945/jn.109.114488

the analysis of the data and wrote different sections of the manuscript. SAZ and AA searched the literature to write the introduction and discussion sections of the manuscript and also edited the manuscript. SR and SST assisted in whole manuscript writing and reviewed it critically in the end. All other authors provided mentorship and approved the final version of the manuscript.

PROVENANCE AND PEER REVIEW

Not commissioned; externally peer reviewed. 